\title{
Role of physical therapy during pregnancy for childbirth preparation
}

\author{
Jéssica da Costa Minati Moraes ${ }^{1 *}$ and Liamara Cavalcante de Assis ${ }^{2}$ \\ ${ }^{1}$ Department of Physiotherapy and Orthopedics, Traumatology and Sports, Brazil \\ ${ }^{2}$ Faculdade Inspirar and Faculdade de Medicina de Marília (FAMEMA), Brazil
}

\begin{abstract}
Background: During pregnancy, a woman's body undergoes various physiological changes. Physical therapy provides to pregnant women a peaceful labor and provides the necessary emotional support and promote well-being and pain relief.

Objective: To evaluate the effect of physical therapy performed during pregnancy for childbirth preparation and its correlation with the time of labor.

Methods: For the study, was selected one pregnant woman, primiparous, between 20 and 35 years, normoglycemic and normotensive, which was evaluated for flexibility by the Wells' bench, and strength of the pelvic floor muscles through the bi-digital test. Then an exercise protocol was applied between the $18^{\text {th }}$ and $36^{\text {th }}$ gestational week.

Results: When evaluated before childbirth, the flexibility was 31 (medium) and strength of pelvic floor muscles (SPFM) was degree 4, the participant was unable to do vaginal delivery because there were complications in the second stage and the realization of abdominal delivery was required. After delivery, the participant was re-evaluated, and flexibility was 36 (good) and the degree of SPFM 4.

Conclusion: Could not verify how physical therapy can influence in the vaginal delivery and decreased pain. However, it is necessary that more studies be conducted in the field of physical therapy in obstetrics.
\end{abstract}

\section{Introduction}

Gestation is an important time in a woman's life, so preparation for the woman who wants to be a mother begins long before pregnancy. It is a unique, intense experience, there are several biological, somatic, psychological and social changes [1]. The body of the woman who is in the gestational period undergoes several physiological changes in all the systems that make up the organism. There are also physical changes, directly related to collagen and involuntary muscle, due to the growth of the belly [2].

These changes occur throughout the pregnancy, lasting 38-40 weeks, or 280 days, and premature birth may occur. Popularly, the gestational period is counted in months, however, the obstetrician counts in weeks, starting from the first day after the last menstruation [3]. The musculoskeletal system of the pregnant woman has significant changes. Posture changes because of the displacement of the center of gravity, since the pregnant woman tends to move forward and the cervical may advance. The pregnant woman also presents flexibility of joints, which are caused by the actions of the hormones. Calcium intake should increase during gestation to maintain bone matrix and connective tissue [2].

When the time of delivery arrives, other physiological changes occur in the body of the pregnant woman. The most significant changes are the dilation of the cervix, contractions generated by hormones, distension of the uterine fibers and the birth canal [4]. Labor is divided into three stages, where the first stage has three subdivisions: initial phase, active phase and transition.
In the initial phase of the first stage is where the dilation of the cervix occurs, the woman will feel contractions, it can last between 12 to 14 hours. The active phase counts the presence of stronger and frequent contractions, approximately every three or four minutes and lasts up to 60 seconds. The second stage begins when the dilation is already 10 centimeters and the baby is born $[5,6]$.

There are several forms of childbirth. In some situations the pregnant woman chooses how she wants her delivery to occur, and in other situations, it is beyond the woman's reach due to the urgency, position of the baby, or risky pregnancy (for example, high blood pressure, diabetes and other health problems). There is the surgical delivery, and the vaginal delivery, where there are different modalities that can be chosen by the pregnant woman like the normal childbirth, natural childbirth, delivery in the water and the labor on squatting position.

During pregnancy, physical therapy may be beneficial for the pregnant woman, helping to prevent discomforts that occur during this period. Kinesiotherapeutic exercises can be performed that will help strengthen the muscles that will help during normal labor, stretching, relaxation, pelvic floor proprioceptive exercises, breathing exercises,

*Correspondence to: Jéssica da Costa Minati Moraes, Department of Physiotherapy and Orthopedics, Brazil, E-mail: jessicaminati@yahoo.com.br

Key words: natural childbirth, obstetrics, parturition, physical therapy, pregnancy

Received: July 25, 2018; Accepted: September 14, 2018; Published: September 20, 2018 
and postural reeducation. For pain relief, methods like hydrotherapy, massage therapy, acupuncture may help relieve low back pain. All strengthening, relaxation and breathing exercises will help in the delivery, helping to reduce the discomforts if the pregnant woman's choice is vaginal delivery. Therefore, it is important to have physical therapy during prenatal care.

As previously mentioned, physiotherapy is of great importance in the prenatal period, as well as in the preparation of labor and during vaginal delivery, promoting relief of pain during the period of contractions and labor, and reduction of labor time, making the moment easier for the pregnant woman and bringing more security to her. Therefore, the objective of the research was to prepare the pregnant women and help in the induction of vaginal delivery, and from the protocol of exercises, teach techniques of breathing, relaxation and strengthening of the pelvic floor muscles, helping to reduce labor time and reduce pain.

\section{Methods}

The method used in this research was the clinical study of a longitudinal case, which was carried out at the Physical Therapy Clinic of Universidade Paulista - UNIP, after approval by the Research Ethics Committee, on February $12^{\text {th }}, 2015$, protocol number 953.541. Two primigravida women, between the age of 20 to 35 years, normoglycemic and normotensive, participated in the study from the $18^{\text {th }}$ week of gestation.

The criteria for non-inclusion are multiparous pregnancies, pregnancies with multiple babies, women with diabetes mellitus or gestational hypertension that were above or below the age limit or with gestational time below the $18^{\text {th }}$ week and above the $36^{\text {th }}$ week. Participants who discontinued treatment or who did not attend the reevaluation were excluded. According to all the criteria, the study was performed with only 1 participant.

The objectives and procedures of the research for the pregnant woman were explained, as well as the interest in participating in the study. After agreeing, she signed the informed consent form. For the study, the pregnant woman was evaluated for flexibility and function of the pelvic floor muscles.

For the evaluation of flexibility, the Wells' bench was used, where the pregnant woman sat with her knees extended and bare feet. Then performed a spinal flexion without the knees being flexed. The value obtained was classified as: $<25$ weak, 26-30 regular, 31-34 medium, 35-38 good and $>40$ optimum, according to the age group of the participant.

For the evaluation of the strenght of the pelvic floor muscles (SPFM), bidigital test was used, where the middle finger and index finger was introduced into the vaginal introitus, and the pregnant woman performed a voluntary contraction of the perineum. The contraction was classified by the modified Oxford Scale: grade 0 - no objective perineal function; grade 1 - recognizable only on palpation; grade 2 - weak palpation; grade 3 - opposing resistance to palpation, but is not maintained; grade 4 - maintains contraction for more than 5 seconds.

Then, initiating the treatment, metabolic exercises were performed to activate the circulation to prevent edema, respiratory exercises to stimulate diaphragmatic breathing, and also taught relaxation techniques, helpfull during labor. Postural guidelines were also given to the pregnant woman.
At the sessions it was done resisted exercises to strengthen the thigh adductor muscles, exercises to strengthen the abdominal muscles with the swiss ball, exercises to strengthen the pelvic floor and perineal muscles - the Kegel contractions technique was used - and respiratory exercises for teach diaphragmatic breathing to pregnant women. During the sessions, massages were applied to the lumbar region according to the patient's complaint of pain, stretching mainly of the gastrocnemius, posterior thigh (biceps femoris, semitendinosus and semimembraneus), paravertebral, sternocleidomastoid, trapezius, biceps and triceps before exercise, and at the end of each session, relaxation exercises were performed.

In total, 56 sessions were performed, being twice a week, during seven months. After three months of delivery, the participant was asked about the type of delivery, the time she remained in labor, whether there was an episiotomy in the case of vaginal delivery and if there was a decrease in pain during labor. Flexibility and SPFM were also reassessed.

At the end of the study, the data were analyzed by specific statistical tests, and the correlation between physiotherapy and the type of delivery was verified.

\section{Results}

Five pregnant women were admitted to the study, of whom only two fit the parameters established by the study. However, one of the patients was excluded because they did not attend the reevaluation, so the study was performed with only one participant.

In relation to the weight, the pre-gestational weight was $74 \mathrm{~kg}$, and presented with $7.2 \mathrm{~kg}$ acquired during pregnancy. After delivery, the baby's birth weight was $2.695 \mathrm{~kg}$. Weight gain may influence the decrease in the SPFM, especially when there is a gravid uterus (Table 1).

The main complaints presented by the pregnant woman were dyspnea, edema in the lower limbs at the end of gestation, increased urinary frequency, low back pain, striae and varicose veins, tiredness and cramps. Other complaints such as the appearance of blemishes on the skin, bleeding gums have also been reported, but with less intensity (Table 2).

The participant was unable to do a vaginal delivery. The labor progressed normally, however, there was intercurrence during the expulsive period, forcing the patient to perform the surgical delivery (Table 3). In the evaluation of the flexibility of the patient with the use of the Wells' bench, in the prepartum it was 31, in the postpartum evaluation it was 36 . In the evaluation of the SPFM through the bidigital test, the prepartum evaluation showed grade 4 , and in the postpartum evaluation presented grade 2 (Table 4 ).

\section{Discussion}

The work of the physiotherapist during the prenatal period is not yet widespread among pregnant women, however, the role of this professional has been important in the preparation of labor and in the relief of discomforts during the gestational period.

The most prevalent complaint among pregnant women is low back pain, this is proven in the study by Santos and Gallo [7], where $73 \%$ of the women complained of low back pain, and reported that the symptoms improved when the rest was performed and techniques of massage therapy. It was reported by the patient that the method helped reduce lumbar pain in the sessions [8]. 
Table 1. Pre-gestational weight, weight acquired during pregnancy, newborn weight

\begin{tabular}{|l|l|}
\hline Weight & Participant \\
\hline Pre-gestational & $74 \mathrm{~kg}$ \\
\hline Acquired during pregnancy & $7.2 \mathrm{~kg}$ \\
\hline Newborn weight & $2.695 \mathrm{~kg}$ \\
\hline
\end{tabular}

Table 2. Gestational complaints

\begin{tabular}{|l|l|l|}
\hline Complaints & Participant & Total \\
\hline Gastric alterations & $\mathrm{X}$ & $100 \%$ \\
\hline Dyspnea & $\mathrm{X}$ & $100 \%$ \\
\hline Edema in the upper limbs & & $0 \%$ \\
\hline Edema in the lower limbs & $\mathrm{X}$ & $100 \%$ \\
\hline Varicose veins & $\mathrm{X}$ & $100 \%$ \\
\hline Carpal tunnel syndrome & & $0 \%$ \\
\hline Increased urinary frequency & $\mathrm{X}$ & $100 \%$ \\
\hline $\begin{array}{l}\text { Urinary incontinence during } \\
\text { pregnancy }\end{array}$ & & $0 \%$ \\
\hline Diabetes during pregancy & & $0 \%$ \\
\hline $\begin{array}{l}\text { Hypertension during } \\
\text { pregnancy }\end{array}$ & & $0 \%$ \\
\hline Constipation & & $0 \%$ \\
\hline Hemorrhoid & $\mathrm{X}$ & $0 \%$ \\
\hline Fecal incontinence & & $0 \%$ \\
\hline Low back pain & $\mathrm{X}$ & $100 \%$ \\
\hline Hair loss & $\mathrm{X}$ & $0 \%$ \\
\hline Stretch marks & & $100 \%$ \\
\hline Feeling tired & $\mathrm{X}$ & $100 \%$ \\
\hline $\begin{array}{l}\text { Increased flow of vaginal } \\
\text { secretion }\end{array}$ & & $0 \%$ \\
\hline $\begin{array}{l}\text { Pain or discomfort in the } \\
\text { breasts }\end{array}$ & & $0 \%$ \\
\hline Bleeding gums & & $100 \%$ \\
\hline Excess salivation & & $100 \%$ \\
\hline Frequent cramps & & \\
\hline Spots on the skin & & \\
\hline & & \\
\hline
\end{tabular}

Table 3. Childbirth forms

\begin{tabular}{|l|l|l|}
\hline Childbirth forms & Participant & Total \\
\hline Surgical & $\mathrm{X}$ & $100 \%$ \\
\hline Vaginal & & $0 \%$ \\
\hline
\end{tabular}

Table 4. Evaluation of flexibility and SPFM in pre and postpartum

\begin{tabular}{|l|l|l|l|l|}
\hline Evaluation & $\begin{array}{l}\text { Flexibility } \\
\text { prepartum }\end{array}$ & $\begin{array}{l}\text { Flexibility } \\
\text { postpartum }\end{array}$ & $\begin{array}{l}\text { SPFM } \\
\text { prepartum }\end{array}$ & $\begin{array}{l}\text { SPFM } \\
\text { postpartum }\end{array}$ \\
\hline Participant & 31 & 36 & 4 & 2 \\
\hline
\end{tabular}

According to Bim et al. [9] the role of the physiotherapist is also important for pregnant women with weakness in the pelvic floor muscles, causing these muscles to be strengthened, favoring the moment of vaginal delivery, since these muscles will participate actively in the expulsive phase. The protocol of exercises applied had a special focus on the strengthening of the pelvic floor through contractions of Kegel, which is the best known and applied technique for the strengthening of this muscle group.

The pregnant woman had some knowledge about the technique of Kegel contractions, but she did not have good proprioception of the perineum, when she was guided about her location and how to perform the contractions, she learned easily, later associating the contractions with respiratory and abdominal exercises.

Vaginal birth may alter SPFM. The study by Barbosa et al. [10] analyzed the influence of the birth canal on the SPFM and concluded that women who performed normal delivery had reduced muscle strength compared to women who had a cesarean delivery. In this study, it was not possible to prove the loss of strength after vaginal delivery, but the patient showed a decrease in strength after cesarean section.

It is not the way of delivery that interferes with the SPFM, but the time of labor, since the participant went into labor, evolved to vaginal delivery, but did not conclude because of the umbilical cord that was wrapped in one of the legs of the baby, making vaginal delivery impossible. As previously mentioned, the work of the physiotherapist in the prenatal and at the time of delivery is not yet widespread, and many pregnant women are not aware that physical therapy can play a fundamental role in their gestational period. Bavaresco et al. [11] sought to show the work of the physiotherapist within obstetrics, not only working on analgesia, but also showing how important is the stimulation of ambulation, breathing exercises that help relaxation and at the time of delivery associated with strength performed by the pregnant woman at the time of the baby's expulsion. Regarding analgesia, the authors propose the use of TENS for pain relief, being placed in the paravertebral and sacral region, but it is not a method used by all physiotherapists, there are several controversies and even the fear of using a device with electric currents in a pregnant woman, even if the electrodes do not stay in the abdominal region. More accepted techniques, and also oriented in the present study, were the adoption of postures that decrease the pain, use of pockets of hot water and hot baths and cryotherapy, in addition to the massages already mentioned in the lumbar region.

The study by Mazzali and Gonçalvez [12] also points the work of the physiotherapist within obstetrics to the orientation of ambulation, respiration, relaxation and also cites the use of TENS as a method of pain relief during labor, stating that this technique will delay the use pain relievers. In talking to the study participant about the use of this technique, she was adverse to the technique, saying that she was very afraid of the use of electric currents during pregnancy, even if they were used in another region of the body, such as in the upper limbs, for example.

\section{Conclusions}

It was not possible to verify that physical therapy can influence the way of delivery, due to an intercurrence during the expulsive period of the participant's labor, occurring in abdominal delivery. It is a fact that the work of the physiotherapist in obstetrics is still being known and still is not very present in the hospitals, however, with the tendency of choosing a humanized birth and preference of many women by the normal birth and also by the incentive of their obstetricians, the work of the physiotherapist in the support to pregnant women in prenatal and labor is much more recognized and sought after, helping the pregnant woman to have a quieter labor and providing the necessary emotional support, besides promoting well-being and relief of pain.

However, more studies are needed to prove how much physiotherapy may influence vaginal delivery.

\section{References}

1. Piccinini CA, Gomes AG, De Nardi T, Lopes RS (2015) Gestação e a Constituição da Maternidade. Psicologia em Estudo, Maringá 13: 63-72.

2. Polden M, Mantle J (2002) Fisioterapia em Ginecologia e Obstetrícia. São Paulo Editora Santos.

3. Pinheiro P (2015) Tempo de Gravidez: Como calcular a idade gestacional. Available at: http://www.mdsaude.com/2014/01/tempo-de-gravidez.html 
4. Pereira RIC (1998) Dor no trabalho de parto: fisiologia e o papel da analgesia peridural. Revista Ciências Médicas Campinas 7: 79-R4.

5. Carrara HHA, Duarte G (1996) semiologia obstétrica. Medicina (Ribeirao Preto. Online) 29: 88-103.

6. Tipos de Parto: As várias formas de dar à luz. [acess 11 oct. 2015] Available at: http:// www.planetabebe.com.br/parto1.php

7. Santos MMD, Gallo AP (2010) Lombalgia gestacional: prevalência e características de um programa pré-natal. Arq Bras Ciên Saúde 35: 174-179.

8. Baracho E (2012) Fisioterapia Aplicada à Saúde da Mulher. $5^{\text {a }}$ edição. Rio de Janeiro: Guanabara Koogan.
9. Bim C, Perego A, Pires Jr H (2007) Fisioterapia aplicada à Ginecologia e Obstetrícia. Iniciação Científica Cesumar.

10. Barbosa AMP, Carvalo LRC, Martins AMVC, Calderon IMP, Rudge MVC (2005) Efeito da via de parto sobre a força muscular do assoalho pélvico. Rev Bras Ginecol Obstet 27: 677-82.

11. Bavaresco GZ, Souza RSO, Almeica B, Sabatino JH, Dias M (2011) O fisioterapeuta como profissional de suporte à parturiente. Ciênc saúde coletiva 16: 7.

12. Mazzali L, Gonçalves R (2008) Análise do tratamento fisioterapêutico na diminuição da dor durante o trabalho de parto normal. Ensaios e Ciência.

Copyright: $\mathbb{C} 2018$ Moraes JCM. This is an open-access article distributed under the terms of the Creative Commons Attribution License, which permits unrestricted use, distribution, and reproduction in any medium, provided the original author and source are credited. 